\title{
Cardiopulmonary-cerebral resuscitation with $100 \%$ oxygen exacerbates neurological dysfunction following nine minutes of normothermic cardiac arrest in dogs
}

\author{
Charles F. Zwemer, Steven E. Whitesall, Louis G. D'Alecy* \\ Department of Physiology and Surgery, 7703 Medical Science Building II, The University of Michigan Medical School, Ann Arbor, \\ MI 48109-0622, USA
}

(Received 14 October 1993; accepted 1 December 1993)

\begin{abstract}
This study investigated the effects of normoxic $\left(\mathrm{F}_{1} \mathrm{O}_{2}=0.21\right)$, hyperoxic $\left(\mathrm{F}_{1} \mathrm{O}_{2}=1.0\right)$, and hyperoxic $\left(\mathrm{F}_{1} \mathrm{O}_{2}=1.0\right)$ plus antioxidant pretreatment (tirilizad mesylate) resuscitation on neurologic outcome following 9 min of normothermic $\left(39 \pm 1.0^{\circ} \mathrm{C}\right)$ cardiac arrest. Physiologic variables including arterial blood gases and neurologic outcome, which was assessed using a standardized scoring system, were followed over a 24-h period following resuscitation from cardiac arrest. Hyperoxically resuscitated dogs sustained significantly worse neurological deficit at 12 and $24 \mathrm{~h}$ (mean scores: $39 \pm 3$ and $49 \pm 8$, respectively) than did antioxidant pretreated hyperoxically resuscitated dogs (mean scores: $22 \pm 1$, $P=0.0007$ and $22 \pm 1, P=0.004$, respectively) and normoxically resuscitated dogs (mean scores: $28 \pm 4, P=0.025$ and $33 \pm 8, P=0.041$ respectively). These data suggest that oxidant injury has a major role in central nervous system dysfunction following successful resuscitation from $9 \mathrm{~min}$ of cardiac arrest. Also, resuscitation from cardiac arrest with hyperoxic $\mathrm{F}_{1} \mathrm{O}_{2}$ 's may contribute to and further exacerbate neurologic dysfunction.
\end{abstract}

Key words: Hyperoxia; Global ischemia and reperfusion; Tirilizad mesylate; Cardiopulmonary resuscitation

\section{Introduction}

Once cardiac function is restored and stabilized, reducing morbidity and mortality in patients who have been successfully resuscitated from cardiac arrest is primarily contingent upon attenuation of central nervous system (CNS) damage. Current clinical understanding places part of the responsibility for this damage on the twofold process of

\footnotetext{
* Corresponding author.
}

ischemia and reperfusion injury [1]. The first phase of CNS damage is thought to occur during stasis of blood flow in the circulatory system and involves the accumulation of ischemic and anaerobic metabolites [1,2]. This is followed by the second phase involving reperfusion and reoxygenation of ischemic tissue and conversion of oxygen $\left(\mathrm{O}_{2}\right)$, by the metabolites, to damaging partially reduced oxygen species (PROS) [1,3]. These PROS are believed to destructively interact with vascular endothelial and neuronal cells and are implicated 
as major contributors to CNS reperfusion injury $[1,4-8,11]$.

Applying this injury mechanism to the specific setting of CPR, it is reasonable to predict an attenuated reperfusion injury and a corresponding improved neurologic outcome from therapies targeted specifically at limiting the production and or activity of reperfusive PROS. Indeed, many investigators have demonstrated that by using radical scavengers such as dimethyl sulfoxide [9], exogenous vitamin E [10], and exogenous antioxidants such as tirilizad mesylate (U74006F) [11], a significant improvement in neurologic outcome could be achieved. While these and other experimental therapies have shown protective promise in CNS injury, most have been targeted at neutralizing PROS activity rather than suppressing or limiting their production. In this study we concentrated our efforts at an earlier stage in the PROS production pathway, namely on the concentration and delivery of reperfusive oxygen, the requisite substrate for PROS.

In the CPR setting, oxygen is ideally delivered to the ischemic tissues from blood with arterial oxygen tensions ranging from $\left(\mathrm{P}_{\mathrm{a}} \mathrm{O}_{2}\right)$ of $80 \mathrm{mmHg}$ in basic life support (BLS) to well over $400 \mathrm{mmHg}$ in advanced cardiac life support (ACLS) [12]. The presumed reasoning behind use of such high fractions of inspired oxygen tension $\left(\mathrm{F}_{\mathrm{I}} \mathrm{O}_{2}\right)$ is the elimination of ischemic tissue hypoxia and anacrobic metabolism [12]. While high reperfusive $\mathrm{P}_{\mathrm{a}} \mathrm{O}_{2}$ may be of metabolic benefit, it may also severely exacerbate reperfusion injury. Considering arterial $\mathrm{PO}_{2}$ 's of at least $200-400 \mathrm{mmHg}$ (used routinely in ACLS and many CPR research models [13-15]), the $\mathrm{PO}_{2}$ difference between reperfusive arterial blood and ischemic CNS tissue would be tremendous. The diffusion equation for $\mathrm{O}_{2}$ transfer from capillary to tissue is a function of the partial pressure difference between the two compartments [16]. Thus, it is this large difference in $\mathrm{PO}_{2}$ which insures a rapid and deep diffusion of $\mathrm{O}_{2}$ into the tissues, however, in the presence of a high concentration of ischemic metabolites, it would also insure the production of destructive PROS. Conceivably, one pass of high $\mathrm{PO}_{2}$ blood would be enough to produce a lethal cellular concentration of PROS. Therefore, we hypothesized that, in contrast to normoxic $\left(\mathrm{F}_{\mathrm{j}} \mathrm{O}_{2}=0.21\right)$, hyperoxic $\left(\mathrm{F}_{\mathrm{i}} \mathrm{O}_{2}=1.0\right) \mathrm{CPR}$ would increase and further exacerbate the extent of neurological dysfunction sustained after successful resuscitation from cardiac arrest.

To test this hypothesis we investigated the effects of normoxic resuscitation $\left(\mathrm{F}_{\mathrm{I}} \mathrm{O}_{2}=0.21\right)$, hyperoxic resuscitation $\left(\mathrm{F}_{\mathrm{I}} \mathrm{O}_{2}=1.0\right)$, and hyperoxic resuscitation plus antioxidant pretreatment $\mathrm{F}_{\mathrm{I}} \mathrm{O}_{2}=1.0$ ) after $9 \mathrm{~min}$ of normothermic cardiac arrest. The antioxidant chosen was tirilizad mesylate (The Upjohn Company, Kalamazoo, MI) which has been shown to be an effective antioxidant both in vitro [32,33] and in vivo [11] as well as having significant neuroprotective effects in the model used in this study. Specifically, tirilizad is believed to reduce PROS-mediated damage by: (1) scavenging lipid peroxyl radicals, (2) directly reacting with hydroxyl radicals, and (3) by direct lipid membrane stabilization $[33,44]$. Thus, reversal of hyperoxia-induced neural damage by tirilizad would indirectly support the conclusion that the damage was PROS mediated. The primary objective of this study then was to determine the extent to which resuscitation and reperfusion $\mathrm{O}_{2}$ tension affected neurological outcome in the $24 \mathrm{~h}$ following cardiopulmonary resuscitation.

\section{Materials and methods}

\subsection{General experimental protocol}

The 27 dogs used in this study were divided into groups of 10 , nine and eight. Each group underwent precisely the same housing, induction, instrumentation, cardiac arrest, resuscitation and recovery procedures with the notable exceptions of fractional inspired oxygen concentration $\left(\mathrm{F}_{\mathrm{i}} \mathrm{O}_{2}=\right.$ 0.21 ) and pre- and post-arrest treatment with antioxidant therapy. The groups were as follows: (N) normoxia, resuscitation with room air $\mathrm{Fi}_{\mathrm{i}} \mathrm{O}_{2}=$ $0.21 ;(\mathrm{H})$ hyperoxia, resuscitation with $\mathrm{F}_{\mathrm{i}} \mathrm{O}_{2}=1.0$; and (HP) hyperoxia with antioxidant therapy, resuscitation with $\mathrm{F}_{\mathrm{i}} \mathrm{O}_{2}=1.0$ and pre- and postarrest treatment with tirilizad mesylate (U74006F, The Upjohn Company, Kalamazoo, MI). A total of $9 \mathrm{mg} / \mathrm{kg} \mathrm{U}$ U4006F was delivered in three equal 
boluses at: 30 min prior to cardiac arrest, immediately following resuscitation, and at $1 \mathrm{~h}$ postarrest. To assess possible derangements in hemodynamic variables and blood gas transport, arterial blood was sampled at 10 time points before and after cardiac arrest. Along with these indices, a well standardized neurological deficit score [11,17-22] was assigned at $1,2,6,12$, and $24 \mathrm{~h}$ post-arrest and resuscitation in all groups.

\subsection{Instrumentation}

Adult male mongrel dogs weighing $15-22 \mathrm{~kg}$ were fasted for $24 \mathrm{~h}$. They were premedicated with $1.5 \mathrm{mg} / \mathrm{kg}$ s.c. morphine sulfate and $20 \mathrm{~min}$ later were anesthetized with $5 \%$ halothane in oxygen via face mask (Foregger, Compact-75, PuritanBennett Corp., Westmont, IL). Upon reaching Stage III Plane 2 of surgical anesthesia, they were orotracheally intubated and mechanically ventilated (Air Shields Ventimeter Ventilator, Hatboro, PA) with 0.75 to $1 \%$ halothane in oxygen for maintenance of surgical anesthesia and suppression of corneal reflexes. No paralytic agents were used.

End-tidal expired $\mathrm{CO}_{2}$ concentration was continuously monitored and maintained between 4 and 5\% (Beckman LB-2, Fullerton, CA) and arterial blood $\mathrm{pH}$ was measured (IL 1304 Blood Gas Analyzer, Lexington, MA) and maintained between 7.38 and 7.41 through adjustment of ventilation and or administration of sodium bicarbonate. Deep esophageal temperature was measured and maintained at $39.0 \pm 1.0^{\circ} \mathrm{C}$ before and for at least $1 \mathrm{~h}$ after resuscitation with a homeothermic blanket system (Model 50-7095, Harvard Apparatus, South Natick, MA) and urinary bladder releases were contained by placement of a urethral catheter.

During instrumentation, each dog received 500 $\mathrm{ml}$ of $0.45 \%$ sodium chloride (Abbott Laboratories, North Chicago, IL) containing $2.52 \mathrm{~g}$ of sodium bicarbonate to assure adequate hydration and normal arterial $\mathrm{pH}$ prior to circulatory arrest. Two venous catheters were inserted; one passed through the left external jugular vein to the right atrium for resuscitation drug administration and the other passed into the proximal caudal branch of the left femoral vein for post-operative/recovery fluid administration $(0.45 \%$ sodium chloride, delivered at $2 \mathrm{ml} /(\mathrm{kg} \times \mathrm{h})$ via continuous intravenous drip (IVAC 530, San Diego, CA). Arterial blood pressure was measured directly and continuously from a catheter placed in the proximal caudal branch of the left femoral artery (Statham P23XL transducer, Gould Inc., Oxnard, CA) and lead II electrocardiogram (ECG) was continuously monitored by placement of subcutaneous disk electrodes (Grass Instrument Co. E5SH Silver Cup Electrodes, Quincy, MA). All catheters and electrical leads were passed subcutaneously to exit the skin at a dorsal midscapular incision for subsequent attachment to a dog jacket and hydraulic/ electric swivel (Alice King Chatham Medical Arts, Los Angeles, CA). A thoracotomy and pericardiectomy were performed at the left fifth intercostal space to provide direct access for both the initiation of cardiac arrest and circumferential cardiac compression during resuscitation. Proper placement of the jugular catheter was established prior to cardiac arrest by direct palpation of the superior vena cava and right atrium. Pulsatile and mean arterial blood pressure (MAP), ECG, and end expiratory $\mathrm{CO}_{2}$ tensions were continuously recorded on a six-channel oscillograph (GouldBrush Model 200, Cleveland, OH).

\subsection{Cardiac arrest}

At the conclusion of instrumentation, halothane administration was halted while ventilation was continued with either room air for animals in the normoxic group or $100 \% \mathrm{O}_{2}$ for animals in the hyperoxic groups (Model 607, Harvard Apparatus, South Natick, MA). This was done to reduce and standardize the level of anesthesia at which ventricular fibrillation was induced. Upon return of corneal reflexes and or limb withdrawal (Stage III, Plane 1 of surgical anesthesia), the heart was fibrillated by the delivery of a $10-$ to $15-\mathrm{s}, 60-\mathrm{Hz}$, 2-ms square-wave stimulus (Model S-9, Grass Medical Instruments, Quincy, MA) to the left ventricular epicardium. Ventilation was discontinued and circulatory arrest was confirmed by ECG, MAP and direct observation of the heart. 


\subsection{Resuscitation and recovery}

Immediately after $9 \mathrm{~min}$ of normothermic ventricular fibrillation, ventilation with room air or $100 \% \mathrm{O}_{2}$, dependent on experimental group, commenced with direct cardiac massage maintaining MAP above $75 \mathrm{mmHg}$. During massage, vasopressor support was initiated by central venous administration of $40 \mu \mathrm{g} / \mathrm{kg}$ epinephrine (Berlex Laboratories Inc., Wayne, $\mathrm{NJ}$ ) and an initial peripheral venous infusion of $20 \mu \mathrm{g} /(\mathrm{kg} \times$ $\mathrm{min}$ ) dopamine (Abbott Laboratories). The central venous bolus of epinephrine was followed in rapid succession by $1 \mathrm{mg} / \mathrm{kg}$ lidocaine (Elkins-Sinn Inc., Cherry Hill, NJ), 4 mequiv./kg sodium bicarbonate, and $25 \mathrm{mg} / \mathrm{kg}$ calcium chloride (American Reagent Laboratories Inc., Shirley, NY). Cardioversion was then attempted by delivery of a 20 to $50-\mathrm{J}$ charge with $31-\mathrm{cm}^{2}$ paddles placed on right and left ventricular surfaces (Lifepak 6 defibrillator/monitor, Physio-Control, Redmond, WA). Additional drugs and or charges were delivered as indicated by MAP and ECG monitoring.

Post-resuscitation dopamine infusion was continued to maintain MAP above $75 \mathrm{mmHg}$ as long as necessary but no longer than $6 \mathrm{~h}$ (typically $<30$ $\mathrm{min})$. A rubber catheter was passed through the chest wall and was sealed in place with a purse suture and connected to intermittent suction (Gomco Thoracic Pump, Gomco Corp., Buffalo, NY) for the removal of excess air and serosanguineous fluid after the chest closure was completed. Mechanical ventilation was continued until spontaneous ventilation resumed (typically $25 \mathrm{~min}$ post-resuscitation) and no later than $6 \mathrm{~h}$ postarrest. Spontaneous ventilation up to the first hour post-arrest was from a non-diffusing gas bag (120 liter Quintron, Milwaukee, WI) containing either room air for normoxically resuscitated animals or $100 \% \mathrm{O}_{2}$ for hyperoxically resuscitated animals. The bag was refilled with either mixture as necessary. At the end of $1 \mathrm{~h}$, all animals breathed room air. The airway was extubated upon return of the gag reflex.

All dogs were given Spectinomycin (Ceva Laboratories Inc., Overland Park, KS), $10 \mathrm{mg} / \mathrm{kg}$ i.m., intraoperatively, and morphine sulfate was provid- ed for analgesia if post-operative attention to wound sites or aggressive behaviors suggested the presence of pain (no animals in this study, however, required such analgesia). Post-operatively, each dog was placed in a jacket and swivel which allowed for free movement about the recovery cage. This arrangement permitted three electrical and three patent hydraulic connections to be made into the dog for long term sampling and hemodynamic measurement. Dogs surviving 24 h postarrest were euthanized with $120 \mathrm{mg} / \mathrm{kg}$ i.v. sodium pentobarbital following the final neurological deficit scoring and sampling procedures. In every dog, a post-mortem examination of the heart, lungs and wound sites was conducted to identify possible iatrogenic complications. Dogs were excluded from this study if their deaths could be attributed to non-neurologic consequences such as aberrant catheter placement, pneumothorax, and excessive hemorrhage.

\subsection{Neurological deficit assessment}

A well-standardized neurologic scoring system was assigned to animals in each group at 1, 2, 6, 12 and $24 \mathrm{~h}$ post-arrest to assess neurologic deficit [11,17-22]. Of a possible 100 points, 18 were assigned to level of consciousness, 18 to respiratory function, 16 to cranial nerve function, 20 to spinal nerve function, and 28 to motor function. Maximum neurological deficit assessed was 100 points and minimal or non-detectable deficit scored 0.

\subsection{Blood sampling}

During the experiment, ten arterial blood samples were removed from the dogs and analyzed for blood gases, $\mathrm{pH}$, hematocrit, and plasma glucose concentrations. The first sample was withdrawn directly after installation of the femoral artery catheter and served as the control. The second and third samples were taken immediately prior to ventricular fibrillation (pre-arrest) and immediately following resuscitation (post-fibrillation), respectively. The seven other samples were removed at $0.5,1,2,4,6,12$, and $24 \mathrm{~h}$ post-arrest. At each of these sampling points, mean arterial blood pres- 
sure (MAP), heart-rate (HR), total urine output volume (up to no later than $6 \mathrm{~h}$ post-arrest), and body temperature (deep esophageal temperature while on operating table; rectal when in recovery cage) were recorded.

\subsection{Statistics}

Comparisons of all physiologic variables were assessed with one way analysis of variance (ANOVA-Scheffe) and neurological deficit scores were compared non-parametrically first using Kruskal-Wallis analysis and then using MannWhitney $U$-analysis to determine individual differences. All average data are expressed as mean \pm one standard error of the mean (S.E.M.) and all statistical calculations were performed on an Apple Quadra 700 computer using the StatView 4.01 Graphic software package.

\subsection{Experimental approval}

The entire experimental procedure conformed to the guidelines set by the American Physiological Society and was approved by the University Committee on the Use and Care of Animals (Approval No. 3271A).

\section{Results}

\subsection{Pre-arrest and resuscitation variables}

All 27 dogs in this study were successfully resuscitated from cardiac arrest as defined by return of spontaneous circulation and maintenance of MAP greater than $75 \mathrm{mmHg}$. Analysis of variance (Scheffe) failed to detect any differences among these groups in pre-arrest or resuscitation variables (Table 1). Also, analysis of variance (Scheffe) was unable to detect statistically significant trends among the three groups in heart rate (HR), MAP, arterial $\mathrm{pH}\left(\mathrm{pH}_{\mathrm{a}}\right)$, arterial $\mathrm{PCO}_{2}$ $\left(\mathrm{P}_{\mathrm{a}} \mathrm{CO}_{2}\right)$, hematocrit (hct) and temperature. While a trend of decreased urine output in the antioxidant pretreated hyperoxic animals appeared compared to normoxic and hyperoxic animals, it was determined statistically insignificant using ANOVA (Scheffe). These physiologic variables appear in tabular form in Table 2.

\subsection{Arterial $\mathrm{PO}_{2}$}

Animals in groups $\mathbf{H}$ and $\mathrm{HP}$ were maintained at statistically significant hyperoxic states relative to normoxic controls before and for $1 \mathrm{~h}$ following

Table 1

Pre-arrest and resuscitation variables

\begin{tabular}{lcrr}
\hline Variable & $\begin{array}{l}\mathrm{H} \\
(n=10)\end{array}$ & $\begin{array}{l}\mathrm{N} \\
(n=9)\end{array}$ & $\begin{array}{l}\mathrm{HP} \\
(n=8)\end{array}$ \\
\hline Body weight $(\mathrm{kg})$ & $16.7 \pm 0.9$ & $18.1 \pm 1.2$ & $14.3 \pm 1.4$ \\
Operative time (min) & $31.3 \pm 3.2$ & $34.8 \pm 5.2$ & $29.9 \pm 6.0$ \\
Resuscitation time (min) & $3.2 \pm 0.8$ & $2.3 \pm 0.3$ & $1.9 \pm 0.3$ \\
Number of countershocks & $2.9 \pm 0.9$ & $2.7 \pm 0.9$ & $1.9 \pm 0.5$ \\
Time on ventilator post resuscitation (min) & $37.4 \pm 4.5$ & $32.6 \pm 1.5$ & $31.3 \pm 1.7$ \\
Time to extubation (min) & $317 \pm 16.8$ & $270 \pm 16.6$ & $268.8 \pm 22.5$ \\
Epinephrine $(\mu \mathrm{g} / \mathrm{kg})$ & $50.0 \pm 5.4$ & $46.7 \pm 4.7$ & $42.5 \pm 2.5$ \\
Lidocaine (mg/kg) & $1.1 \pm 0.1$ & $1.1 \pm 0.1$ & $1.0 \pm 0.0$ \\
Sodium bicarbonate (mequiv./kg) & $4.8 \pm 0.5$ & $4.4 \pm 0.4$ & $4.8 \pm 0.5$ \\
Calcium chloride (mg/kg) & $25.0 \pm 0.0$ & $27.8 \pm 2.8$ & $28.0 \pm 2.1$ \\
Duration of dopamine infusion (min) & $24.9 \pm 2.9$ & $29.3 \pm 7.0$ & $21.8 \pm 2.7$ \\
Survival (h) & $23.5 \pm 0.5$ & $23.9 \pm 0.1$ & $24 \pm 0.0$
\end{tabular}

Average pre-arrest and resuscitation data (mean \pm S.E.M). Groups were compared by pairwise comparison using ANOVA (Scheffe). Resuscitation time $=$ time untill MAP $>75 \mathrm{mmHg}$ without mechanical assistance; $n=$ sample size. 


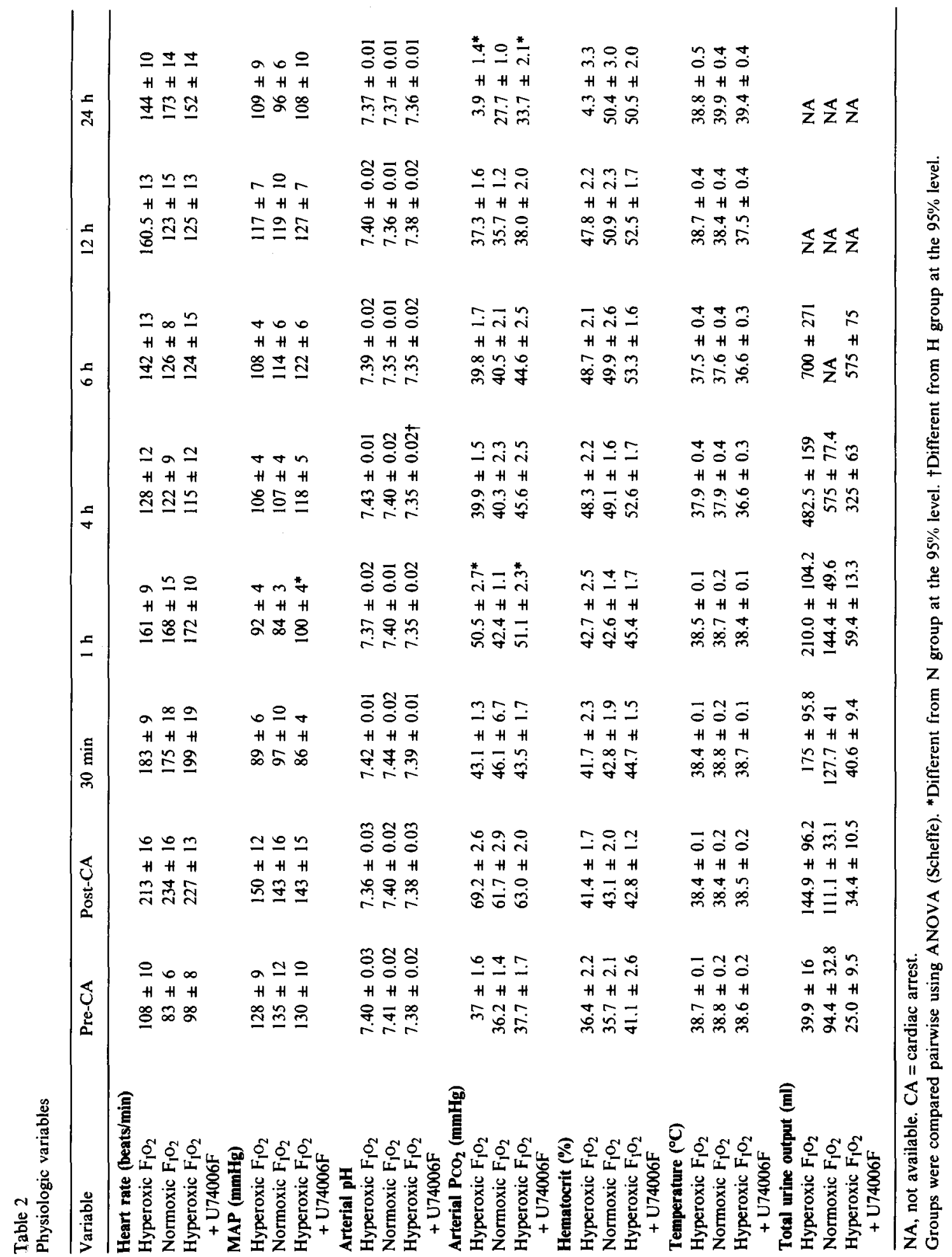


resuscitation from cardiac arrest as seen in Fig. 1. Of note, was the significantly lower $\mathrm{P}_{\mathrm{a}} \mathrm{O}_{2}$ among hyperoxic dogs relative to hyperoxic pretreated dogs at the immediate post resuscitation sampling point detected by ANOVA (Scheffe). In addition, $\mathrm{P}_{\mathrm{a}} \mathrm{O}_{2}$ of both hyperoxic groups fell from approximately 450 to $250 \mathrm{mmHg}$ at $1 \mathrm{~h}$ regardless of a maintained $\mathrm{F}_{\mathrm{I}} \mathrm{O}_{2}=1.0$. Using a paired Student's $t$ test, $\mathrm{P}_{\mathrm{a}} \mathrm{O}_{2}$ was found to be significantly lower than prefibrillatory values at immediately post-resuscitation $(P=0.0013)$ and $1 \mathrm{~h}(P=0.0041)$ in the $\mathrm{H}$ group. Using the same statistical comparison on the $\mathrm{HP}$ group, 30 min and $1 \mathrm{~h}$ mean $\mathrm{P}_{\mathrm{a}} \mathrm{O}_{2}$ 's were found to be significantly lower $(P=0.046$ and $P=0.0079$, respectively) than prefibrillatory values as well.

\subsection{Arterial blood glucose}

No statistically significant differences in arterial blood glucose among groups throughout the 24-h experiment were detectable using ANOVA (Scheffe). Of note is the trend toward elevated post-resuscitation plasma glucose concentrations in both groups of hyperoxically resuscitated animals compared to their normoxic counterparts.

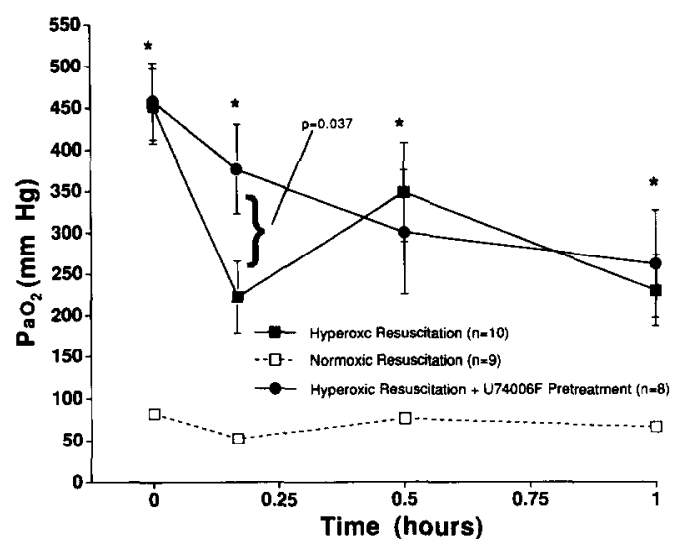

Fig. 1. Mean \pm S.E.M. of $\mathbf{P}_{\mathrm{a}} \mathrm{O}_{2}$ for all three groups versus time. ANOVA (Scheffe) confirmed that both $\mathrm{H}$ and $\mathrm{HP}$ group animals were hyperoxically maintained at a higher $\mathrm{P}_{\mathrm{a}} \mathrm{O}_{2}$ before and for $1 \mathrm{~h}$ after cardiac arrest and resuscitation than normoxic controls. *Significance at $P<0.04$. Of note is the postresuscitation difference among $\mathrm{H}$ and $\mathrm{HP}$ groups $(P<0.037)$. Sample size, unless otherwise noted, is indicated in the figure. S.E.M. bars for the $\mathbf{N}$ group occur within the symbols.

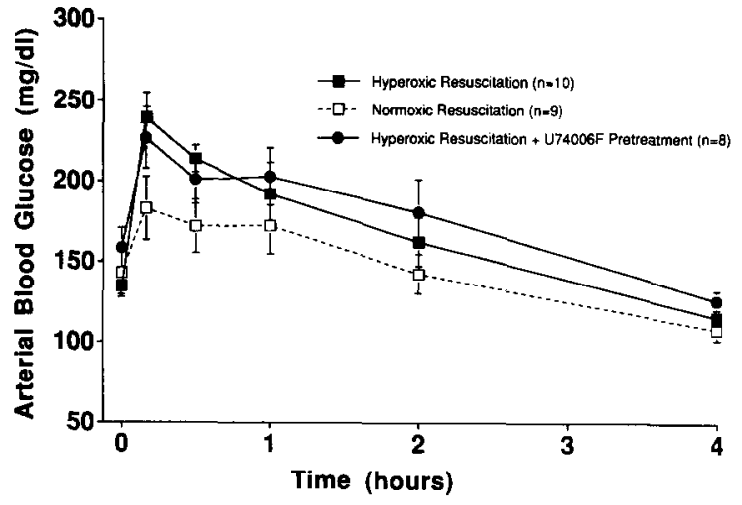

Fig. 2. Mean \pm S.E.M. of arterial blood glucose for all three groups versus time. ANOVA (Scheffe) failed to detect any difference among groups. However, unpaired comparison using two-tailed $t$-tests revealed that $\mathrm{N}$ group dogs were significantly lower than $\mathrm{H}$ group dogs at post-resuscitation $(P=0.035)$ and $0.5 \mathrm{~h}(P=0.033)$. Sample size, unless otherwise noted, is given in the figure.

Fig. 2 describes the arterial blood glucose values for all animals in the first $4 \mathrm{~h}$ following cardiac arrest, after which they were indistinguishable.

\subsection{Neurologic deficit}

All animals survived at least $19 \mathrm{~h}$ post-arrest. One animal in the normoxic group and two from the hyperoxic group died between 19 and $24 \mathrm{~h}$ and were assessed an NDS of 100 at $24 \mathrm{~h}$ as their deaths were directly attributable to a primary neurological insult. No animals from the antioxidant-pretreated, hyperoxically resuscitated group died prematurely, however this did not reach statistical significance with the Fischer's Exact test $(P=0.4771)$.

A Kruskal-Wallis (non-parametric) analysis detected significant differences in neurological deficit score (NDS) among the three groups in all but the 2 -h time point following resuscitation at $P<0.003$. Further non-parametric analysis using the Mann-Whitney $U$-test revealed the HP group had the greatest neurological improvement throughout the 24-h post-resuscitation period. While the average NDS tended to be lower (significantly lower at the $1-\mathrm{h} P=0.003$ and the 6- 


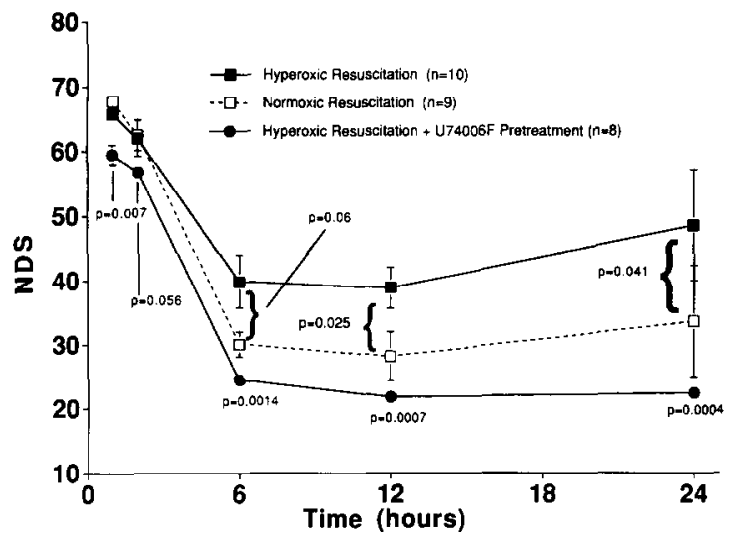

Fig. 3. Mean \pm S.E.M. of post-arrest neurologic deficit score $(0=$ no deficit, $100=$ maximum deficit $)$ for all three groups versus time. Sample size, unless otherwise noted, is given in the figure. Mean NDS scores were consistently lower for animals in $\mathrm{HP}$ and $\mathrm{N}$ at 6,12 , and $24 \mathrm{~h}$ than in $\mathrm{H}$ animals. Significance values for these means were derived from the Mann-Whitney $U$-test. S.E.M. bars for the HP group occur within the symbols.

h $P=0.024)$ in the antioxidant treated group than the normoxic group the pattern did not reach statistical significance at the 12- and 24-h points. Both N and HP groups showed significantly lower neurological deficits at the 12- and 24-h points than did animals in the $\mathrm{H}$ group. These results appear graphically as NDS versus time in Fig. 3.

\section{Discussion}

Resuscitation from cardiac arrest is associated with an abysmal survival rate (current overall survival rates of between 2 and $20 \%$ are typical) $[23,24]$. Central to the success of CPR is the reduction of the degree of CNS damage [1]. While the pathophysiologic mechanisms responsible for primary CNS damage before, during and after resuscitation are multiple, a relatively large body of evidence exists implicating reperfusive PROS damage in brain microvascular and neuronal injury $[1-8,10]$.

Briefly, many of the reactive species of $\mathrm{O}_{2}$ are believed to be generated during reperfusion after the ischemic episode. Accumulation of ischemic metabolites such as purines, free ferrous iron, hydrogen ions, and arachidonic acid metabolites have been shown, through various enzymecatalyzed reactions, to transform reperfusion $\mathrm{O}_{2}$ into PROS both in vitro and in vivo $[1,4,5,25,26]$. In the CPR setting, these ischemic metabolites are believed to accumulate during global cerebral ischemia resulting from cardiac arrest, and during resuscitation contribute to the transformation of $\mathrm{O}_{2}$ into lethal PROS [1]. Once formed, these lethal PROS destructively interact with membrane phospholipids, thus destroying endothelial and possibly neuronal cells, which leads to an inappropriate fluid/electrolyte exchange ultimately leading to further and diffuse tissue damage and necrosis.

Hence, we postulated that by maximizing the reperfusing $\mathrm{P}_{\mathrm{a}} \mathrm{O}_{2}$ we would substantially increase neurological deficit. Indeed, as Fig. 3 shows, hyperoxic resuscitation for one hour on $100 \%$ oxygen significantly increased the severity of neurological deficit following $9 \mathrm{~min}$ of normothermic cardiac arrest. The association of high resuscitation $\mathrm{F}_{\mathrm{i}} \mathrm{O}_{2}$, and subsequently high $\mathrm{P}_{\mathrm{a}} \mathrm{O}_{2}$ and arterial $\mathrm{O}_{2}$ content, with a significantly greater neurologic deficit is consistent with our hypothesis and fits very well into presumed mechanisms of PROS production [1]. Furthermore, the neurologic dysfunction was significantly attenuated by antioxidant pretreatment in the period of hyperoxia and in a separate group by normoxic resuscitation. Presumably in the former case (HP), the PROS destructive interaction was halted by the presence of tirilizad, a known inhibitor of lipid peroxidation $[32,33]$ and in the latter case $(\mathrm{N})$, damage was attenuated by the reduction in available $\mathrm{O}_{2}$ substrate.

Much of reperfusion oxidant injury is believed to occur within the first minutes of recirculation $[1,11]$. This being the case, we ventilated the dogs in each group with appropriate $\mathrm{F}_{\mathrm{i}} \mathrm{O}_{2}$ out to $1 \mathrm{~h}$ post-arrest in order to insure $\mathrm{O}_{2}$ would be present at the desired tension. Interestingly, $\mathrm{P}_{\mathrm{a}} \mathrm{O}_{2}$ 's in all groups dropped between prefibrillitory control and immediate post-resuscitation time points. Variables possibly responsible for this drop include: increased diffusion distance, decreased area available for diffusion, and ventilation/perfusion mismatching. At the immediate post-resuscitation point, spontaneous circulation had been restored and MAP > $75 \mathrm{mmHg}$, such that the pressure 
head for perfusion of the lungs was probably adequate. Resuscitation time (Table 1) was not different among groups however the $\mathrm{H}$ group tended to have a prolonged resuscitation time. Additionally, contributing factors such as reduced cardiac output and lung atelectasis (thus decreased overall diffusion area) could have been responsible. Alternatively, the lung microvasculature and parenchyma could have undergone transient reperfusive PROS injury. Perfusion of isolated lungs with solutions containing xanthine and xanthine oxidase (known ischemic metabolites), in the presence of $\mathrm{O}_{2}$, results in increases in the pulmonary capillary filtration coefficient and subsequent pulmonary edema $[36,37]$. Thus, pulmonary edema could be responsible for an increased diffusion distance and result in a decreased $\mathrm{P}_{\mathrm{a}} \mathrm{O}_{2}$. While this was not measured in our study, it is interesting to note that the largest drop in $\mathrm{O}_{2}$ tension occurred in the hyperoxic group (presumably sustaining the greatest oxidant injury) and the lowest relative drop was recorded in the antioxidant pretreated group.

Regardless of the mechanism of drop in $\mathrm{P}_{\mathrm{a}} \mathrm{O}_{2}$, animals in the hyperoxic group remained hyperoxic throughout the entire designated period. Normoxically resuscitated animals, even though resuscitated with $\mathrm{F}_{1} \mathrm{O}_{2}=0.21$ however, became relatively hypoxic $(53 \pm 4 \mathrm{mmHg})$ at the immediate post-resuscitation point and ironically, this may have contributed to their improved outcome. Reduction of $\mathrm{P}_{\mathrm{a}} \mathrm{O}_{2}$ to this hypoxic level places the loading of hemoglobin on the shoulder or even steep portion of the dissociation curve [43]. The functional significance of this being the reduction not only of $\mathrm{P}_{\mathrm{a}} \mathrm{O}_{2}$ but of absolute blood $\mathrm{O}_{2}$ content. Hence, the protective effect (relative to the $\mathrm{H}$ group) observed in normoxic resuscitation may have been the result of a reduction in the amount of $\mathrm{O}_{2}$ delivered to the tissues and thus available for conversion to PROS. Supporting this argument; post-ischemic hypoxia $\left(\mathrm{P}_{\mathrm{a}} \mathrm{O}_{2}\right.$ of $40-50$ $\mathrm{mmHg}$ ) has been shown to improve metabolic and functional recovery of the spinal cord as well as attenuate post-ischemic microvascular injury in skeletal muscle [38,39]. Although initially counterintuitive, the concept of hypoxic resuscitation should be further investigated.
- Hyperoxia as a contributing factor to tissue damage is not a recent idea. As far back as the mid 70 's and early 80's, hyperoxic tissue homogenates were shown to produce damaging hydrogen peroxide [31,34] and superoxide [34]. However, the notion of hyperoxic exacerbation of reperfusion injury is relatively recent. In 1989 Wolbarsht and Fridovich hypothesized that hyperoxia was a significant contributor during reperfusion injury [35]. Hyperoxia, according to their hypothesis, was derived from normoxic blood entering ischemic tissues which acidified the blood, through Bohr effects, thereby forcing $\mathrm{O}_{2}$ off hemoglobin drive up local $\mathrm{P}_{\mathrm{a}} \mathrm{O}_{2}$ [35]. While our study supports their general hypothesis it is impossible to determine from our data, the role or extent to which Bohr effect-hemoglobin chemistry figures in the neurological insult.

Another possible contributing factor to $\mathrm{CNS}$ damage sustained by hyperoxically resuscitated dogs involves post-resuscitation hyperglycemia. Pre- and post-arrest hyperglycemia has been associated with a severely detrimental neurological outcome $[17,40]$. As seen in Fig. 2, elevated glucose levels were present in hyperoxically resuscitated animals as compared to their normoxic counterparts in this study. While repeated measures ANOVA failed to detect differences among these groups, the two tailed unpaired $t$-tests indicated that the $\mathbf{H}$ group had a higher blood glucose concentration. The mechanism and impact of this elevated plasma glucose concentration on resuscitation outcome in this investigation is unknown but has been previously reported as being clearly detrimental in this setting [17,19-21].

Critically evaluating our model, it is possible that prearrest and or resuscitation variables somehow affected neurological outcome in pretreated and normoxically resuscitated dogs prior to or during arrest. Statistical analyses in Tables 1 and 2 along with Fig. 1 address this possibility. With the notable exception of $\mathrm{F}_{\mathrm{i}} \mathrm{O}_{2}$ (Fig. 1), Tables 1 and 2 demonstrate no statistically discernible difference in pre-arrest or resuscitation variables. Of critical importance in CPR models, is the pre-arrest maintenance of body temperature within normal canine range. This is because hypothermic protection of tissues from 
ischemia/reperfusion injury by precooling tissues using moderate $\left(33^{\circ} \mathrm{C}\right)$ to subtle $\left(35^{\circ} \mathrm{C}\right)$ drops in temperature $[18,30]$ has been demonstrated. Canine body temperature is normally $39 \pm 1.0^{\circ} \mathrm{C}$ [27-29] and is not $37^{\circ} \mathrm{C}$, or lower, at which many investigators routinely manage canine resuscitation models [13,14]. While their work may demonstrate significant therapeutic insight it must be interpreted cautiously due to the possible confounding influence of relative hypothermia. In our model, body temperature was rigorously maintained well within normal canine values as seen in Table 2.

\section{Conclusions}

Data from this study clearly indicate the importance of controlling $\mathrm{F}_{\mathrm{I}} \mathrm{O}_{2}$ in this model of CPR. As well, the data provide compelling evidence linking reperfusive PROS to CNS dysfunction in the post-resuscitative setting from cardiac arrest. The possible clinical implications of this study concern the absolute and rigorous use of $100 \% \mathrm{O}_{2}$ to resuscitate victims of cardiac arrest. Current ACLS guidelines state that the 'highest possible oxygen concentration (preferably $100 \%$ ) should be administered as soon as possible to all patients with cardiac or pulmonary arrest...' $[12,41]$. This hyperoxic therapy may counter the hypoxemia experienced during circulatory arrest [42], but it may also increase the probability of PROS production and subsequent damage as shown experimentally in our study. It is fully understood that every clinical case is unique and are never as cleanly controlled (most do not involve open-chest direct cardiac massage or antioxidant pretreatment) as in the research setting of a laboratory. However, these data still may have important and significant ramifications for the practice of CPR. It is currently unknown, either clinically or experimentally, what $\mathrm{F}_{1} \mathrm{O}_{2}$ produces the least PROS while maintaining tissue viability.

This study confirmed the hypothesis that hyperoxic resuscitation from 9 min of normothermic cardiac arrest is associated with a significantly increased neurological deficit. While hyperoxia is associated with poor outcome, normoxic and antioxidant pretreated hyperoxically resuscitated ani- mals showed significant improvements in neurological outcome. Implicated in causing this drastic difference in outcomes are PROS which may be produced at a much greater rate in settings of hyperoxic reperfusion. Thus, while it may seem counterintuitive, high resuscitation $\mathrm{F}_{\mathrm{i}} \mathrm{O}_{2}$ 's may be a significant contributor to severity of reperfusion injury and thus be adversely impacting upon CPR survival rates.

\section{Acknowledgments}

This work was supported, in part, by a grant from the American Heart Association of Michigan (G10934) and a gift from The Upjohn Company of Kalamazoo, Michigan. Dr. Zwemer was supported by an NIH, NRSA (F32 HL08792-01) postdoctoral fellowship. A special thanks to the Physio-Control Corporation of Redmond, Washington for the generous donation of the Lifepak-6 defibrillator. The authors also wish to thank Mary C. Lloyd, Natasha K. Eaddy and Jason A. Pollack for their excellent and expert technical assistance throughout this research project.

\section{References}

1 Traystman RJ, Kirsch JR, Koehler RC. Oxygen radical mechanisms of brain injury following ischemia and reperfusion. J App Physiol 1991; 71 (4): 1185-1195.

2 Brierly JB, Meldrum BS, Brown AW. The threshold and neuropathology of cerebral "anoxic-ischemic" cell change. Arch Neurol 1973; 29: 367-374.

3 Pulsinelli WA, Brierley JB, Plum F. Temporal profile of neuronal damage in a model of transient forebrain ischemia. Ann Neurol 1982; 11: 491-498.

4 Armstead W, Mirro R, Busija D, Leffler CW. Postischemic generation of superoxide anion by newborn pig brain. Am J Physiol 1988; 255 (Heart Circ Physiol 240): H401-H403.

5 Inauen W, Payne D, Kvietys P, Granger D. Hypox$\mathrm{ia}$ /reoxygenation increases the permeability of endothelial cell monolayers: role of oxygen free radicals. Free Rad Biol Med 1990; 9: 219-223.

6 Hart C, Tolson J, Block E. Supplemental fatty acids alter lipid peroxidation and oxidant injury in endothelial cells. Am J Physiol 1991; 260 (Lung Cell Mol Physiol 4): L481-L488.

7 Lum H, Barr DA, Shaffer JR, Gordon RJ, Ezrin AM, Malik AB. Reoxygenation of endothelial cells increases 
permeability by oxygen dependent mechanisms. Circ Res 1992; 70: 991-998.

8 McCord JM. Oxygen derived free radicals in postischemic tissue injury. N Engl J Med 1985; 312 (3): 159-163.

9 Coles JC, Ahmed SN, Mehta HU, Kaufman JCE. Role of radical scavenger in protection of spinal cord during ischemia. Ann Thorac Surg 1986; 41: 551-556.

10 Yamamoto M, Shima T, Uozumi T, Sogabe T, Yamada $K$, Kawasaki T. A possible role of lipid peroxidation in cellular damage caused by cerebral ischemia and the protective effect of alpha tocopherol administration. Stroke 1983; 14: 977-982.

11 Natale JE, Schott RJ, Hall ED, Braughler JM, D'Alecy LG. Effect of the aminosteroid U74006F after cardiopulmonary arrest in dogs. Stroke 1988; 19 (11): 1371-1378.

12 Emergency cardiac care committee and subcommittees, American Heart Association. Guidelines for cardiopulmonary resuscitation and emergency cardiac care. III. Adult advanced cardiac life support. I Am Med Assoc 1992; 268: 2199-2241.

13 Cerchiari EL, Safar P, Klein E, Cantadore R, Pinsky M. Cardiovascular function and neurologic outcome after cardiac arrest in dogs. The cardiovascular postresuscitation syndrome. Resuscitation 1993; 25: 9-33.

14 Cerchiari EL, Safar P, Klein E, Diven W. Visceral, hematologic, and visceral post-resuscitation syndrome. Resuscitation 1993; 25: 119-136.

15 Eleff SM, Schleien CL, Koehler RC, Shaffner DH, Tsitlik J, Halperin HR, Rogers MC, Traystman RJ. Brain bioenergetics during cardiopulmonary resuscitation in dogs. Anesthesiology 1992; 76: 77-84.

16 Dejours P. Oxygen and carbon dioxide exchanges by diffusion, ch 5. Principles of comparative respiratory physiology, 2nd ed. Amsterdam: Elsevier, 1981.

17 Lundy EF, Kuhn JE, Kwon JM, Zelenock GB, D'Alecy LG. Infusion of $5 \%$ dextrose increases mortality and morbidity following six minutes of cardiac arrest in dogs. $\mathrm{J}$ Crit Care 1987; 2 (1): 4-14.

18 Natale JE, D'Alecy LG. Protection from cerebral ischemia by brain cooling without reduced lactate accumulation in dogs. Stroke 1989; 20: 770-777.

19 Natale JE, D'Alecy LG. Continued circulatory support: effect of epinephrine or dopamine in $24 \mathrm{~h}$ survival and neurologic function in dogs. Resuscitation 1989; 17 : 273-286.

20 Schott RJ, Natale JE, Ressler SW, Burney, D'Alecy LG. Neutrophil depeletion fails to improve neurologic outcome after cardiac arrest in dogs. Ann Emerg Med 1989; 18: $517-522$.

21 Natale JE, Stante SM, D'Alecy LG. Elevated brain lactate accumulation and increased neurologic deficit are associated with modest hyperglycemia in global brain ischemia. Resuscitation 1990; 19: 271-289.

22 Facktor MA, Mayor GH, Nachreiner RF, D'Alecy LG. Thyroid hormone replacement during resuscitation from cardiac arrest in dogs. Resuscitation 1993; 26: 141-162.

23 Becker LB, Ostrander MP, Rarret I, Kondos GT. Out- come of CPR in a large metropolitan area-Where are the survivors? Ann Emerg Med 1991; 20: 355-361.

24 Becker LB. Mcthodology in cardiac arrest research sym posium. Ann Emerg Med 1993; 22: 1-3.

25 Imaizumi S, Kayama T, Suzuki J. Chemiluminescense in hypoxic brain - the first report. Correlation betyween energy metabolism and free radical reaction. Stroke 1984; 15 (6): 1061-1065.

26 Zhong Z, Lemasters JJ, Thurman RG. Role of purines and xanthine oxidase in reperfusion injury in perfused rat liver. J Pharmacol Exp Ther 1988; 250: 470-475.

27 Robard S. Weight and body temperature. Science 1950; 111: 465.

28 Addendum of physiologic variables. Merck veterinary manual, 5th ed. Rahway, NJ: Merck and Company Inc., 1979; 1482-1483.

29 Feigl EO, D'Alecy LG. Normal arterial blood pH, oxygen and carbon dioxide tensions in unanesthetized dogs. $\mathbf{J}$ Appl Physiol 1972; 32 (1): 152-153.

30 Pelky TJ, Frank RS, Stanley JJ, Frank TS, Zelenock GB, D'Alecy LG. Minimal physiologic temperature variations during renal ischemia alter functional and morphologic outcome. J Vasc Surg 1992; 15 (4): 619-625.

31 Boveris A, Chance B. The mitochondrial generation of hydrogen peroxide: general properties and effect of hyperbaric oxygen. Biochem J 1973; 134: 707-716.

32 Braughler JM, Pregenzer JF, Chase RL, Duncan LA, Jacobsen EJ, McCall JM. Novel 21-aminosteroids as potent inhibitors of iron-dependent lipid peroxidation. $J$ Biol Chem 1987; 262: 10438-10440.

33 Braughler JM, Chase RL, Neff GF, Yonkers PA, Day JS, Hall ED, Sethy VH, Lahti RA. A new 21-aminosteroid antioxidant lacking glucocorticoid activity stimulates ACTH secretion and blocks arachidonic acid release from mouse pituitary tumor (AtT-20) cells. J Pharmacol Exp Ther 1988; 244: 423-427.

34 Freeman BA, Topolosky MK, Crapo JD. Hyperoxia increases oxygen radical production in rat lung homogenates. Arch Biochem Biophys 1982; 216 (20): 477-484.

35 Wolbarsht ML, Fridovich I. Hyperoxia during reperfusion is a factor in reperfusion injury. Free Rad Biol Med 1989; 6: 61-62.

36 Barnard ME, Matalon S. Mechanisms of extracellular reactive oxygen species injury to the pulmonary microvasculature. J Appl Physiol 1992; 72 (5): 1724-1729.

37 Barnard JW, Patterson CE, Hull MT, Wagner WW, Rhodes RA. Role of microvascular pressure in reactive oxygen-induced lung edema. J Appl Physiol 1989; 66: 1486-1493.

38 Danielisova V, Marsala $\mathbf{M}$, Chavko $\mathbf{M}$, Marsala J. Postischemic hypoxia improves metabolic and functional recovery of the spinal cord. Neurology 1990; 40: 1125-1129.

39 Korthuis RJ, Smith JK, Carden DL. Hypoxic reperfusion attenuates postischemic microvascular injury. Am J Physiol (Heart Circ Physiol 25) 1989; 256: H315-H319. 
40 D’Alecy LG, Lundy EF, Barton KJ, Zelenock GB. Dextrose containing intravenous fluid impairs outcome and increases death after $8 \mathrm{~min}$ of cardiac arrest and resuscitation in dogs. Surgery 1986; 100: 505-511.

41 Cardiovascular pharmacology I. In: Textbook of advanced cardiac life support, 2 nd ed. Dallas, TX: American Heart Association, 1990; 97-110.

42 Ayers SM. Mechanisms and consequences of pulmonary edema. Cardiac lung, shock lung, and principles of venti- latory therapy in adult respiratory distress syndrome. Am Heart J 1982; 103: 97-112.

43 Woodson RD, Fitzpatrick JH, Costello DJ, Gilobe DD. Increased blood oxygen affinity decreases canine brain oxygen consumption. J Lab Clin Med 1982; 100: 411-424.

44 Hall ED, Yonkers PA, Andrus PK, Cox JW, Anderson DK. Biochemistry and pharmacology of lipid antioxidants in acute brain and spinal cord injury. J Neurotrauma 1992; 9 Suppl 2: S425-S442. 